\title{
Characterization of an NGF-P-TrkA Retrograde-Signaling Complex and Age-Dependent Regulation of TrkA Phosphorylation in Sympathetic Neurons
}

\author{
Brian A. Tsui-Pierchala and David D. Ginty \\ Department of Neuroscience, The Johns Hopkins University School of Medicine, Baltimore, Maryland 21205-2185
}

Nerve growth factor (NGF) is a target-derived trophic factor for developing sympathetic and cutaneous sensory neurons. NGF promotes growth and survival of neurons via activation of the receptor tyrosine kinase TrkA. We used compartmentalized cultures of sympathetic neurons to address the mechanism of NGF signaling from distal axons and terminals to proximal axons and cell bodies. Our results demonstrate that an NGFphospho-TrkA (NGF-P-TrkA)-signaling complex forms in distal axons and is retrogradely transported as a complex to cell bodies of sympathetic neurons. Although a minor fraction of both NGF and TrkA is retrogradely transported, a large fraction of the NGF that is retrogradely transported is found complexed with retrogradely transported TrkA. Interestingly, the metabolism of the P-TrkA complex is dramatically different in young, NGF-dependent sympathetic neurons as compared to older, NGF-independent sympathetic neurons. After withdrawal of

Developing neurons rely heavily on trophic support provided by their environment, and one of the main sources of neurotrophic factors is the targets of neuronal innervation (Levi-Montalcini, 1987; Barde, 1989; Oppenheim, 1991; Korsching, 1993). The first identified, and prototypic, target-derived neurotrophic factor is nerve growth factor (NGF), which supports the survival of developing sympathetic and cutaneous sensory neurons (Reichardt and Farinas, 1997). NGF belongs to a family of neurotrophic factors termed the neurotrophins, which includes brain-derived neurotrophic factor (BDNF), neurotrophin-3 (NT-3), neurotrophin-4/5 (NT-4/5), and neurotrophin-6 (Bothwell, 1995).

The neurotrophins promote survival and differentiation of developing neurons via activation of the receptor tyrosine kinases TrkA, TrkB, and TrkC, which bind with high affinity to NGF, BDNF and NT-4/5, and NT-3, respectively (Snider, 1994; Reichardt and Fariñas, 1997). NT-3 can bind to and activate TrkA and TrkB as well. Binding of NGF to TrkA results in the dimerization and trans-phosphorylation of multiple tyrosine residues in TrkA (Kaplan and Stephens, 1994; Greene and Kaplan,

Received March 17, 1999; revised July 7, 1999; accepted July 12, 1999.

This work was supported by National Institutes of Health (NIH) National Research Service Award MH11868 to B.A.T.-P. and by NIH Grant NS34814, the American Cancer Society Junior Faculty Research Award 603, and a Pew Scholars Award to D.D.G. We thank Ruben Adler, Alex Kolodkin, Richard Mains, Fabio Rupp, Cynthia Tsui-Pierchala, and members of the Ginty laboratory for discussions and critical reading of this manuscript.

Correspondence should be addressed to Dr. David D. Ginty, Department of Neuroscience, The Johns Hopkins University School of Medicine, PCTB Room 1000, 725 North Wolfe Street, Baltimore, MD 21205-2185.

Copyright @ 1999 Society for Neuroscience 0270-6474/99/198207-12\$05.00/0
NGF from distal axons of young neurons, P-TrkA within distal axons, as well as within proximal axons and cell bodies, dephosphorylates rapidly. In contrast, after withdrawal of NGF from distal axons of older neurons, P-TrkA within distal axons dephosphorylates completely, although more slowly than that in young neurons, whereas dephosphorylation of P-TrkA within proximal axons and cell bodies occurs markedly more slowly, with at least one-half of the level of P-TrkA remaining $2 \mathrm{~d}$ after NGF withdrawal. Thus, P-TrkA within the cell bodies of young, NGF-dependent sympathetic neurons is derived from distal axons. A more stable P-TrkA complex within cell bodies of mature sympathetic neurons may contribute to the acquisition of NGF independence for survival of mature sympathetic neurons.

Key words: NGF; TrkA; sympathetic neurons; retrogradesignaling complex; tyrosine phosphorylation; signal transduction
1995; Segal and Greenberg, 1996), which act as docking sites for intracellular effectors of Trk receptors.

Although much is known about Trk receptor signaling mechanisms, the mechanisms by which neurotrophin signals are propagated from axon terminals to cell bodies to promote survival and differentiation remain unresolved. This issue has been investigated using both cell culture systems and animal models. NGF was first suggested to have a role in retrograde signaling after the observation that ${ }^{125} \mathrm{I}-\mathrm{NGF}$ is retrogradely transported from the terminals of sympathetic neurons innervating the iris to cell bodies within the superior cervical ganglion at a rate of $\sim 2.5$ mm/hr (Hendry et al., 1974; Korsching and Thoenen, 1983). ${ }^{125} \mathrm{I}-\mathrm{NGF}$ is also retrogradely transported from distal axons to cell bodies of sympathetic neurons grown in compartmentalized cultures at a rate of $\sim 3-20 \mathrm{~mm} / \mathrm{hr}$ (Claude et al., 1982; Ure and Campenot, 1997). Similarly, the rate at which a retrograde NGF signal travels to regulate phosphorylation and activation of cAMP response element-binding protein (CREB), a nuclear transcription factor implicated in NGF function, is $3-6 \mathrm{~mm} / \mathrm{hr}$ (Riccio et al., 1997). Furthermore, internalization of NGF from axon terminals is necessary for propagation of the NGF signal to CREB in sympathetic neurons (Riccio et al., 1997), supporting the idea that NGF itself is a component of a retrograde signal in sympathetic neurons.

In addition to studies implicating NGF, recent evidence has implicated Trk receptors as components of the retrograde neurotrophin signal. Tyrosine-phosphorylated TrkB accumulates in sciatic nerve after injection of BDNF into peripheral tissue (Bhattacharyya et al., 1997), and phospho-TrkA (P-TrkA) also accumulates distal to ligation or crush of the sciatic nerve (Ehlers 
et al., 1995; Johanson et al., 1995). Furthermore, P-TrkA accumulates in cell bodies of sympathetic neurons grown in compartmentalized cultures after exposure of distal axons and terminals to NGF (Riccio et al., 1997; Senger and Campenot, 1997). Thus, an NGF-TrkA complex may be retrogradely transported to regulate biochemical events in the cell body. However, the rapid retrograde appearance of phosphorylated Trk receptors has been described (Bhattacharyya et al., 1997; Senger and Campenot, 1997), raising the possibility that phosphorylated Trks may travel in a rapidly transported vesicle or by a vesicle-independent mechanism. Alternatively, a molecule(s) other than NGF may propagate the retrograde signal from axon terminals to TrkA located in cell bodies. In an attempt to distinguish between these possibilities, we asked whether the NGF-TrkA complex that forms in distal axons and terminals is retrogradely transported intact to cell bodies. Our results provide direct evidence that NGF and TrkA are retrogradely cotransported from terminals to cell bodies of sympathetic neurons. Furthermore, we report that the regulation of phosphorylation of TrkA is profoundly influenced by the age of sympathetic neurons. The latter observation may provide insight into mechanisms underlying the acquisition of NGF independence for survival of mature sympathetic neurons observed both in vitro and in vivo.

\section{MATERIALS AND METHODS}

Compartmentalized and mass sympathetic neuronal cultures. Superior cervical ganglia were dissected from postnatal day 1 (P1) to P3 Sprague Dawley rats, enzymatically dissociated, and plated onto collagen-coated tissue culture dishes as described previously (Mains and Patterson, 1973). Neurons were maintained in growth medium consisting of DMEM supplemented with fetal bovine serum $(10 \%)$, penicillin $(1 \mathrm{U} / \mathrm{ml})$, streptomycin (1 U/ml), and NGF (100-200 ng/ml). NGF was purified from male submaxillary glands as described (Mobley et al., 1976). Sympathetic neurons were maintained for the first 1-2 weeks in culture in growth medium containing cytosine arabinoside $(10 \mu \mathrm{M})$ to remove nonneuronal, mitotically active cells. Compartmentalized cultures were established essentially as described (Campenot, 1982). Briefly, Camp 10 Teflon dividers (Tyler Research, Edmonton, Alberta, Canada) were carefully attached to collagen-coated $35 \mathrm{~mm}$ culture dishes (Falcon) using silicone vacuum grease (Dow Corning). One drop of medium containing methylcellulose $(1 \%)$ was placed onto the plate before setting the divider onto the culture dish, which facilitated axon growth underneath the silicon grease barriers (Campenot, 1982). The integrity of the grease seals was assessed by placing culture medium into side chambers only and incubating the chambers overnight in a $37^{\circ} \mathrm{C}$ incubator. Cells were only plated into chambers that did not leak. Cells $(60,000-70,000)$ were placed into central compartments of compartmentalized chambers in a small volume and were allowed to adhere for 2 or more hours. The central compartment was next filled with growth medium, and the side compartments remained empty. The compartmentalized cultures were incubated overnight, and the integrity of intercompartmental seals was reconfirmed by assessing whether medium had leaked into other compartments. In addition to using the Camp 10 Teflon dividers, we designed larger dividers, termed biochemistry chambers, for the purpose of performing biochemical analyses of cellular lysates obtained from a greater number of neurons. Biochemistry chamber cultures were prepared for sympathetic neuronal cultures in an identical manner as described above, except that the chambers were placed into $60 \mathrm{~mm}$ collagen-coated culture dishes and 250,000 cells were seeded into each chamber. Two to three biochemistry chamber cultures provided a sufficient amount of cellular material for immunoblot and/or immunoprecipitation/immunoblot experiments, whereas neuronal extracts prepared from eight or more Camp 10 chamber cultures were required for each condition in these experiments. Sympathetic neurons grown in biochemistry chambers required at least 3 weeks in vitro to generate sufficient amounts of distal axons and terminals for immunoprecipitation/immunoblot experiments. Results from sympathetic neurons maintained in Camp 10 compartmentalized cultures were identical to results obtained from cultures grown in biochemistry chambers, demonstrating that differences in the geometries of the two types of Teflon dividers did not lead to differences in responses of the neurons.

Sympathetic neuron stimulations and immunoprecipitations. Mass cultures of sympathetic neurons or individual compartments of compartmentalized cultures of sympathetic neurons were stimulated with NGF $(200 \mathrm{ng} / \mathrm{ml})$ for the times indicated. For the stimulation of compartmentalized cultures [12-14 d in vitro (DIV)], cell body compartments were incubated with growth medium lacking NGF but containing a rabbit polyclonal NGF antibody (1:2000; Sigma, St. Louis, MO) for 36-48 hr. In some experiments (see Fig. $1 A, C$ ), compartments containing distal axons and terminals were placed in medium containing a low concentration of NGF $(2 \mathrm{ng} / \mathrm{ml})$ for $48 \mathrm{hr}$ before addition of NGF $(200 \mathrm{ng} / \mathrm{ml})$ to distal processes and terminals. To determine the kinetics of TrkA dephosphorylation after removal of NGF from the distal axons and terminals, we removed NGF from the terminal compartments, washed the processes once with medium without NGF, and then incubated the processes with medium containing polyclonal anti-NGF (1:2000; Sigma) for the times indicated in the figures. For Trk immunoprecipitation or immobilized streptavidin precipitation experiments, cultures were incubated with polyclonal anti-NGF for $7 \mathrm{hr}$ for young, 12 DIV neurons and $24 \mathrm{hr}$ for older, 35 DIV neurons in all compartments before stimulation. After cultures were stimulated with NGF, they were washed twice with ice-cold Tris-buffered saline (TBS) and lysed for $25 \mathrm{~min}$ at $4^{\circ} \mathrm{C}$ with TBS containing Nonidet P-40 (1\%), glycerol (10\%), leupeptin (10 $\mu \mathrm{g} / \mathrm{ml})$, aprotinin $(1 \mu \mathrm{g} / \mathrm{ml})$, PMSF $(500 \mu \mathrm{M})$, and sodium orthovanadate $(1 \mathrm{~mm})$, as described previously (Kaplan et al., 1991). All subsequent steps were performed at $4^{\circ} \mathrm{C}$. Lysates from several plates were pooled and subsequently clarified by centrifugation at $13,000 \mathrm{rpm}$ in a microfuge for 15 min. Then, supernatants were subjected to immunoprecipitation using affinity-purified Trk polyclonal antibodies (1:100 dilution C14; Santa Cruz Biotechnology, Santa Cruz, CA) and 50-70 $\mu$ l of a Protein Aagarose slurry (Santa Cruz Biotechnology). The suspension was gently rotated for at least $2 \mathrm{hr}$; immune complexes were collected by centrifugation, washed three times in lysis buffer, and resolved by SDS-PAGE.

Cell surface biotinylation and streptavidin precipitations. Cell surface proteins were biotinylated by incubating the sympathetic neuronal cultures with sulfo-NHS-LC-biotin (2 mM; Pierce, Rockford, IL) in PBScontaining glucose $(1 \mathrm{mg} / \mathrm{ml})$ for $30 \mathrm{~min}$ at $4^{\circ} \mathrm{C}$. Cultures were then washed twice with ice-cold PBS containing glucose to remove excess sulfo-NHS-LC-biotin, returned to $37^{\circ} \mathrm{C}$, and treated with either medium alone or medium containing NGF (200 $\mathrm{ng} / \mathrm{ml})$ for the indicated times. After treatment, cultures were washed twice with ice-cold TBS, and cellular lysates were prepared as described above. After removal of insoluble proteins, supernatants were incubated overnight at $4^{\circ} \mathrm{C}$ with $70-100 \mu \mathrm{l}$ of a $50 \%$ slurry of streptavidin-agarose (Pierce). The biotinstreptavidin-agarose complexes were collected after centrif ugation and washed three times in lysis buffer, and the complexes were resolved by SDS-PAGE. In some experiments, the clarified supernatants were further subjected to Trk immunoprecipitation as described above.

Coimmunoprecipitation of ${ }^{125} I-N G F$ with TrkA. Distal axons and terminals of neurons grown in compartmentalized cultures were incubated with medium containing ${ }^{125} \mathrm{I}-\mathrm{NGF}$ (40 ng/ml; specific activity, 3.03 $\mathrm{MBq} / \mu \mathrm{g}$; New England Nuclear) in the presence or absence of unlabeled NGF (500 ng/ml) for $8 \mathrm{hr}$. Cell extracts from the various compartments were prepared as described above, and bound ${ }^{125} \mathrm{I}-\mathrm{NGF}$ was covalently cross-linked to TrkA by incubating cell extracts in PBS containing NP40 $(0.25 \%)$, glycerol $(10 \%)$, leupeptin, aprotinin, sodium orthovanadate, and bisuccidimyl suberate $\left(\mathrm{BS}^{3} ; 2 \mathrm{~mm}\right)$ for $2 \mathrm{hr}$ at $4^{\circ} \mathrm{C}$. Then, excess $\mathrm{BS}^{3}$ was quenched after the addition of Tris $(100 \mathrm{~mm}$; $\mathrm{pH} 7.4)$ for an additional $30 \mathrm{~min}$ at $4^{\circ} \mathrm{C}$. The lysates were then clarified by centrifugation, and supernatants were subjected to streptavidin precipitations or Trk immunoprecipitations as described above. In some experiments (see Fig. $4 C, D), \mathrm{BS}^{3}$ was omitted from the reaction because it was found that ${ }^{125}$ I-NGF and TrkA could be efficiently coprecipitated without previous cross-linking. The presence of the $180 \mathrm{kDa}{ }^{125} \mathrm{I}-\mathrm{NGF}-\mathrm{TrkA}$ cross-linked complex was dependent on the inclusion of $\mathrm{BS}^{3}$ in the reaction. Precipitated proteins were resolved on $15 \%$ SDS-polyacrylamide gels, and gels were dried and subjected to autoradiography.

Immunoblot analysis and antibodies. TrkA immunoprecipitates or streptavidin precipitates were resolved on SDS-polyacrylamide gels $(8 \%)$, and proteins were transferred to polyvinylidene difluoride membranes. After the membranes were washed with TBS containing $0.05 \%$ Tween 20 (TBST), the immunoblots were blocked for $1 \mathrm{hr}$ at room temperature with TBST containing 4\% heat-inactivated horse serum (HS). The immunoblots were next incubated with TBST containing 4\% 
HS and primary antibody for 2 additional hours at room temperature or overnight at $4^{\circ} \mathrm{C}$. Blots were then washed three times with TBST containing $0.5 \% \mathrm{HS}$ and incubated at room temperature for $1 \mathrm{hr}$ with TBST containing $4 \%$ HS and secondary antibody $(1: 10,000$ dilution of either anti-mouse or anti-rabbit IgG horseradish peroxidase; Boehringer Mannheim, Indianapolis, IN). Blots were washed three additional times, as described above, and visualized using a chemiluminescent detection method (Supersignal; Pierce). For blots with very low signal intensities, the same procedure was followed, except with more stringent washes, including an additional $1 \mathrm{hr}$ wash between the primary and secondary antibody incubations and an additional $3 \mathrm{hr}$ wash in TBS containing 1\% HS and $0.3 \%$ Tween 20 after the secondary antibody incubation. Also, the dilution of HRP-conjugated secondary antibody used for these detections was 1:50,000, and signals were visualized using the Blaze (Pierce) chemiluminescent substrate. For phosphotyrosine immunoblots, the primary antibody solution consisted of a combination of 4G10 (1: 2000 dilution; Upstate Biotechnology, Lake Placid, NY) and PY99 (1:2000 dilution; Santa Cruz Biotechnology) in TBST containing 4\% BSA or $4 \%$ HS. TrkA immunoblot analysis was done using Trk C14 (1:200 dilution; Santa Cruz Biotechnology). In most cases, protein normalization was done by assessing the amount of $\alpha$-tubulin by immunoblot analysis using $\alpha$-tubulin antibodies (1:20,000; Sigma), as described previously (Senger and Campenot, 1997). It was necessary to use $\alpha$-tubulin rather than $\alpha$-Trk for normalizations because none of the seven different Trk antibodies tested could reliably detect the small amounts of TrkA in immunocomplexes from the relatively small numbers of neurons used for these experiments. When very large numbers of neurons were used (see experiments in Fig. $1 B$ ), TrkA was detectable by immunoblot and used for normalizations. For some immunoprecipitation experiments, the C14 Trk antibody used was obtained from rabbits immunized with the $\mathrm{C} 14$ peptide, which consists of the C-terminal 14 residues of TrkA, conjugated to thyroglobulin using glutaraldehyde. Anti-Trk was affinitypurified from the serum of hyperimmunized rabbits using an affinity column made with the C14 peptide conjugated to Affigel-10 (Bio-Rad, Hercules, CA). It should be noted that the relative molecular mass and NGF sensitivity of P-TrkA levels detected in anti-Trk immune complexes collected with four different Trk antibodies [C14 anti-Trk (Santa Cruz Biotechnology), our C14 anti-Trk, anti-Trk Ab 203 (kindly provided by Dr. David Kaplan, MNI), and anti-Trk 1048 (kindly provided by Dr. William Mobley, University of California at San Francisco)] were identical. Other antibodies used for immunoblots, including $\alpha$-Src, $\alpha$-Shc, $\alpha$-phosphatidylinositol-3 kinase ( $\alpha$-PI-3K), $\alpha$-Grb-2, and $\alpha$-Rsk-2, were obtained from Santa Cruz Biotechnology. Anti-phospholipase C (PLC)- $\gamma$ was from Upstate Biotechnology, and anti-TH was from East Acres Biologicals. For some experiments (see Fig. 2), each of the antibodies used recognized one prominent protein band of the appropriate relative molecular mass. Each of the individual immunoblots used for this figure was cropped to show only the relevant band.

\section{RESULTS}

\section{P-TrkA forms a complex with tyrosine-phosphorylated} proteins in both cell bodies and terminals

Treatment of distal axons and terminals of sympathetic neurons with NGF leads to the appearance of P-TrkA in cell bodies (Riccio et al., 1997; Senger and Campenot, 1997). Yet, whether the P-TrkA detected within cell bodies and proximal axons of sympathetic neurons was derived from TrkA that was retrogradely transported from the distal axons has been controversial. An effective way of addressing this and related questions about retrograde NGF signaling is via biochemical analyses using immunoprecipitation and immunoblotting techniques. Therefore, we developed methods to perform biochemical analyses of sympathetic neurons grown in conventional compartmentalized cultures as well as neurons grown in larger biochemistry chambers, which were designed for this purpose. Neurons were grown in medium containing a low concentration of NGF $(2 \mathrm{ng} / \mathrm{ml})$ for $2 \mathrm{~d}$, which reduced the levels of P-TrkA (data not shown). After exposure of distal axons and terminals of sympathetic neurons grown in compartmentalized cultures to NGF $(200 \mathrm{ng} / \mathrm{ml})$ for 1 $\mathrm{hr}$, the levels of P-TrkA in cell bodies increased, as determined by immunoprecipitation of TrkA followed by phosphotyrosine immunoblotting (Fig. 1 $A$ ). Inductions were typically two- to fourfold under these conditions, and we further detected an interesting correlation between the age of the neurons in vitro and the magnitude of induction of phosphorylation of TrkA after NGF treatment (see below). These results confirm previous observations that P-TrkA appears in cell bodies after exposure of distal axons and terminals of sympathetic neurons to NGF (Riccio et al., 1997; Senger and Campenot, 1997).

To compare the nature of the TrkA-signaling complex that forms in cell bodies with that that forms in distal axons of sympathetic neurons, we treated the cell body or distal axon and terminal compartments of 35 DIV sympathetic neurons grown in compartmentalized cultures with NGF, immunoprecipitated TrkA under nondenaturing conditions, and subjected immune complexes to phosphotyrosine immunoblot analysis. After treatment of cell bodies with NGF, TrkA and at least seven TrkAassociated proteins became tyrosine phosphorylated (Fig. 1B). NGF treatment of axon terminals also activated TrkA, and an identical pattern of Trk-associated, tyrosine-phosphorylated proteins was detected (Fig. 1B). These results indicate that similar TrkA-signaling complexes are formed in these two cellular compartments. Similar results were obtained in experiments using younger NGF-dependent 12 DIV neurons grown in compartmentalized cultures, although the relative intensities of some of the TrkA-associated phosphoproteins differed (data not shown).

Next, we asked whether P-TrkA within cell bodies, which is regulated by NGF applied to distal axons and terminals, is associated with substrates. Cell extracts were made from both the cell body and distal process compartments of over 30 conventional compartmentalized cultures of 12 DIV NGF-dependent sympathetic neurons that were supported by NGF present only in medium bathing distal axons and terminals. TrkA was immunoprecipitated under nondenaturing conditions, and the immune complexes were subjected to phosphotyrosine immunoblotting. P-TrkA coprecipitated with proteins of $\sim 75,41$, and $38 \mathrm{kDa}$ from extracts prepared from cell bodies (Fig. 1C). In contrast, P-TrkA and its coprecipitating substrates were undetectable in TrkA immune complexes derived either from compartmentalized 12 DIV neurons that were exposed to anti-NGF in all compartments or from neurons grown in mass cultures (data not shown). Taken together, these results indicate that the amount of tyrosinephosphorylated TrkA within the cell bodies of young, NGFdependent neurons is controlled by NGF acting at distal axons and terminals and that this P-TrkA within cell bodies can associate with at least some of its substrates.

As a first step toward characterizing TrkA-signaling complexes in cell bodies and axon terminals of sympathetic neurons, we sought to establish whether known substrates and downstream effectors of TrkA are located in the cell bodies and/or distal processes of sympathetic neurons. Immunoblot analyses were performed on cellular extracts collected from either cell bodies and proximal axons or distal axons and terminals of sympathetic neurons grown in compartmentalized cultures that were maintained with NGF on their distal processes (Fig. 2). TrkA was found enriched in distal axons and terminals compared with cell bodies. Some of the known substrates of TrkA, including Shc, PLC- $\gamma$, rAPS, and SHP-2 were localized in cell bodies as well as in distal axons; SHP-2 was enriched in distal axons. Downstream TrkA effectors PI-3K, Grb-2, mitogen-activated protein kinase (MAPK), and Src were also found in both cell bodies and distal axons and terminals, and like TrkA, Src was more abundant in 


\section{A}

Figure 1. Tyrosine phosphorylation of TrkA and downstream effectors in cell bodies and distal axons and terminals of sympathetic neurons. $A$, The distal axons and terminals of 28 DIV sympathetic neurons grown in biochemistry chambers were placed in medium containing low NGF $(2 \mathrm{ng} / \mathrm{ml})$ for $2 \mathrm{~d}$ before treatment with medium alone $(-)$ or medium containing NGF (200 ng/ml; +) for $1 \mathrm{hr}$. TrkA was immunoprecipitated from cell lysates prepared from individual compartments, and the immunoprecipitates were subjected to phosphotyrosine immunowere performed on the supernatants from the immunoprecipitates (bottom) to demonstrate equal amounts of total protein in the extracts. $B$, Thirty-five DIV sympathetic neurons grown in biochemistry chambers were placed in medium containing low NGF $(2 \mathrm{ng} / \mathrm{ml})$ for $2 \mathrm{~d}$ before treatment with either control medium $(-)$ or $200 \mathrm{ng} / \mathrm{ml} \mathrm{NGF}(+)$ directly on the cell bodies $(C B)$ or distal axons and terminals ( $T$ ) for $10 \mathrm{~min}$. Extracts were subjected to the same analysis described in $A$. To demonstrate equal amounts of proteins in the two cell body compartments and in the two distal axon compartments, the phosphotyrosine immunoblot (top) was stripped and reprobed with an antibody against Trk (bottom). C, Thirty-three 12 DIV cultures of compartmentalized neurons were maintained for $2 \mathrm{~d}$ in medium containing anti-NGF in the cell body compartment and in medium containing NGF $(200 \mathrm{ng} / \mathrm{ml})$ in the terminal compartment. Lysates prepared from individual compartments of all 33 cultures were pooled and subjected to Trk immunoprecipitation and phosphotyrosine immunoblotting analysis (top). Proteins in supernatants of immunoprecipitates were subjected to antiphosphotyrosine (middle) and $\alpha$-tubulin (bottom) immunoblotting. IP, Immunoprecipitate; Term, terminals; $W$, Western blot. blotting (top). $\alpha$-Tubulin immunoblots
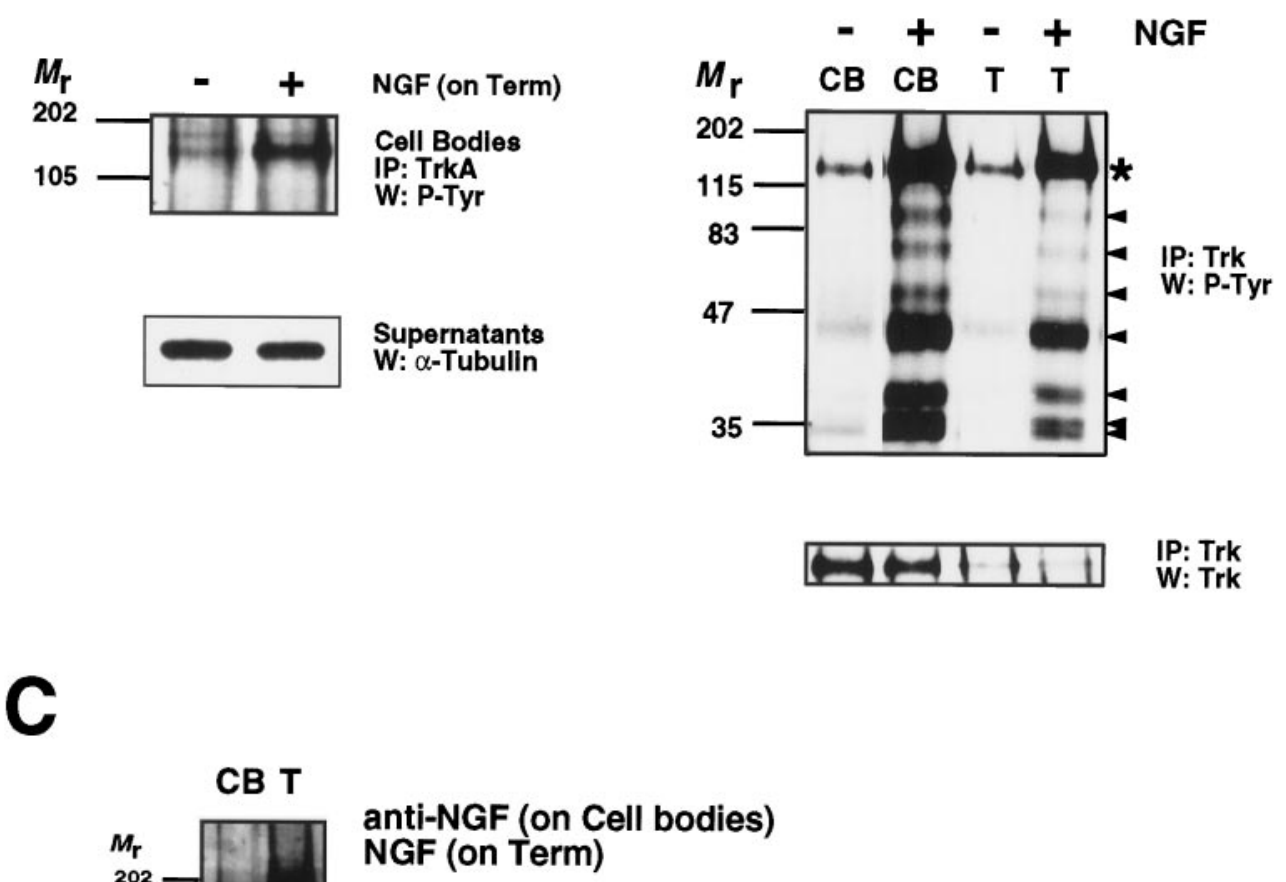

distal axons than in cell bodies. Some substrates of TrkA, such as APS and Shc, migrated more slowly on SDS-PAGE when extracted from the distal axon compartment, possibly because of enhanced post-translational modifications, perhaps by tyrosine phosphorylation. Taken together, these data demonstrate that TrkA and several of its substrates and effectors are present in cell bodies and proximal axons as well as in distal axons and terminals.

\section{P-TrkA that appears in cell bodies is derived from distal axons}

Because P-TrkA that is present in cell bodies and proximal axons of young, NGF-dependent neurons is dependent on the presence of NGF in the medium bathing the distal axons and terminals, we sought to determine whether P-TrkA is retrogradely transported from the terminals or whether it is derived from TrkA localized

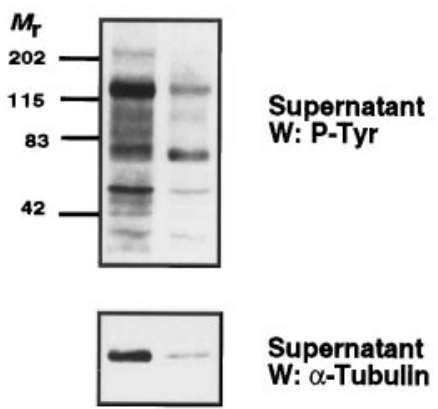

previously in cell bodies. To distinguish between TrkA located in the plasma membrane of distal axons and terminals and TrkA located in the plasma membrane of cell bodies, we biotinylated cell surface proteins in one or the other of these two compartments. To establish proper conditions, we performed cell surface biotinylation first on mass cultures of sympathetic neurons, which were incubated with either of two concentrations of membraneimpermeant NHS-LC-Biotin for $30 \mathrm{~min}$ at $4^{\circ} \mathrm{C}$. The cultures were then thoroughly washed and treated with $\mathrm{NGF}$ at $37^{\circ} \mathrm{C}$ for an additional $10 \mathrm{~min}$. Subsequently, biotinylated TrkA and other cell surface-biotinylated proteins were precipitated with immobilized streptavidin and subjected to phosphotyrosine immunoblotting. Immobilized streptavidin precipitated an NGF-dependent, tyrosine-phosphorylated protein of $140 \mathrm{kDa}$ (Fig. $3 A$ ). This biotinylated $140 \mathrm{kDa}$ phosphoprotein is TrkA because it precisely
B

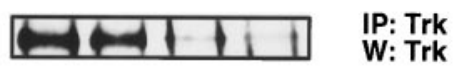




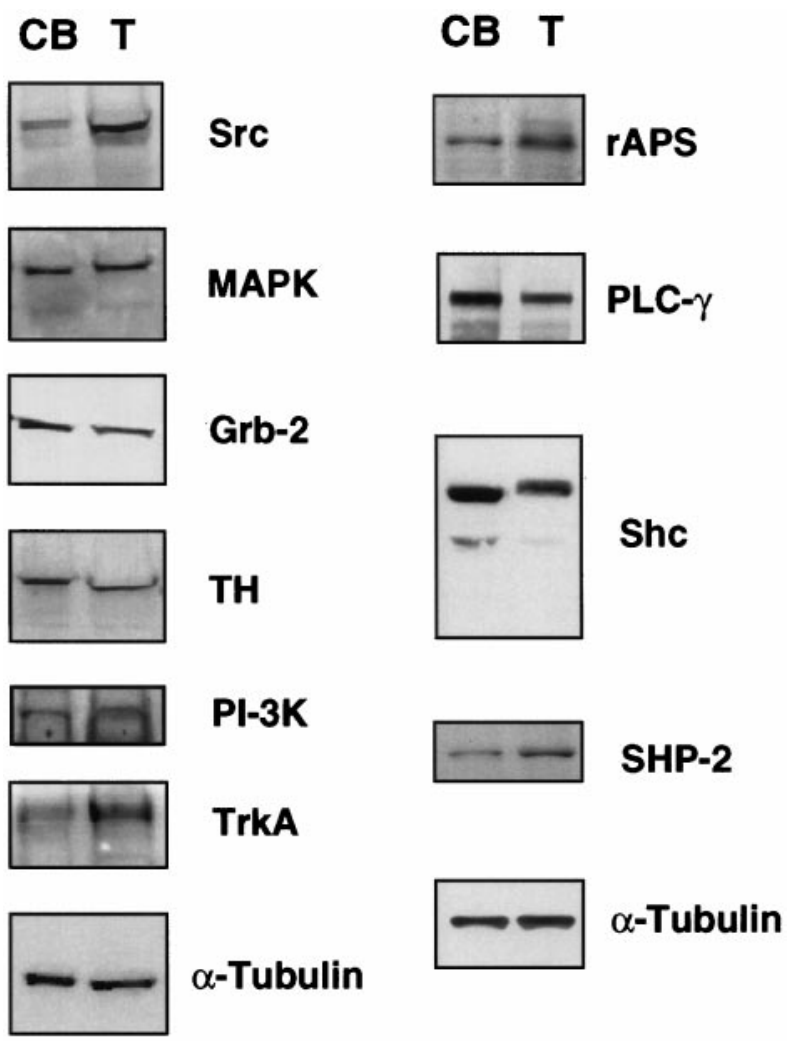

Figure 2. Distribution of TrkA and some of its effector molecules in sympathetic neurons. Thirty-five DIV sympathetic neurons grown in biochemistry chambers were maintained with NGF present only in the medium in distal axons and terminal compartments for 2 weeks before lysis. Cellular extracts prepared from the $C B$ and $T$ compartments were subjected to immunoblot analysis using the several different antibodies shown in the figure and described in Materials and Methods. Each column represents the entire lysate prepared from sympathetic neurons from 8 to 10 biochemistry chambers, and the proteins analyzed are listed on the right of the immunoblot.

comigrated with P-TrkA (Fig. 3B), its tyrosine phosphorylation was NGF-dependent (Fig. 3A,B), and immobilized streptavidin completely depleted the lysates of P-TrkA (Fig. $3 A$ ). NGF treatment of cell surface-biotinylated mass cultures of sympathetic neurons resulted in tyrosine phosphorylation of several proteins detected in the supernatants of the TrkA immunoprecipitations (Fig. 3B). These results demonstrate that biotinylated TrkA was catalytically active and able to activate downstream tyrosine phosphorylation events.

To determine whether P-TrkA that accumulates within cell bodies after exposure of distal axons and terminals to NGF is derived from distal axons, we biotinylated cell surface proteins only in distal axon compartments of 12 DIV sympathetic neurons and treated the distal axons and terminals with NGF. After $2 \mathrm{hr}$ of treatment of distal axons with NGF, biotinylated proteins were precipitated from both the cell body and axon terminal compartments and analyzed by phosphotyrosine immunoblotting. P-TrkA precipitated with immobilized streptavidin from extracts prepared from the terminal compartments after NGF treatment (Fig. $3 C$ ). Importantly, P-TrkA was also precipitated with immobilized streptavidin from cell bodies, but only after treatment of distal axons with NGF (Fig. 3C). Therefore, P-TrkA that appears in the cell bodies and proximal axons is derived, at least in part, from TrkA initially present in the distal axons and terminals. These results indicate that $\mathrm{P}-\mathrm{TrkA}$ is retrogradely transported in sympathetic neurons. Probing of the immunoblots with an antibody directed against TrkA showed that biotinylated TrkA is detected in cell bodies and proximal axons only after treatment of the terminals with NGF (data not shown).

We next asked whether TrkA located on the plasma membrane of cell bodies and proximal axons becomes tyrosine phosphorylated after treatment of distal axons and terminals with NGF. Cell surface proteins in the cell body compartments were biotinylated. Then, NGF was applied to either cell bodies or distal axons for $2 \mathrm{hr}$, and immobilized streptavidin precipitations and phosphotyrosine immunoblotting were performed. Application of NGF directly to cell bodies led to tyrosine phosphorylation of biotinylated TrkA (Fig. 3D). In contrast, after application of NGF to distal axons for $2 \mathrm{hr}$, tyrosine-phosphorylated, biotinylated TrkA was not detected in extracts prepared from the cell bodies and proximal axons (Fig. 3D). Taken together, these results indicate that P-TrkA is retrogradely transported from distal axons and terminals to cell bodies.

\section{NGF remains bound to retrogradely transported P-TrkA}

Experiments were performed to determine whether NGF remains bound to retrogradely transported P-TrkA. To detect NGF bound to TrkA, we first treated mass cultures of sympathetic neurons with medium containing ${ }^{125} \mathrm{I}-\mathrm{NGF}(40 \mathrm{ng} / \mathrm{ml})$ or ${ }^{125} \mathrm{I}$ NGF (40 ng/ml) and excess unlabeled NGF (500 ng/ml). TrkA was immunoprecipitated after incubation of lysates with a watersoluble, covalent cross-linking agent $\left(\mathrm{BS}^{3}\right)$ to cross-link NGF covalently to TrkA. The immune complexes were resolved by SDS-PAGE, and the dried gel was subjected to autoradiography. Under these conditions, ${ }^{125}$ I-NGF coprecipitated with TrkA from sympathetic neurons, and nonradiolabeled NGF competed with ${ }^{125}$ I-NGF (Fig. 4A). The Trk antibodies specifically coprecipitated ${ }^{125}$ I-NGF because preincubation of the Trk antibodies with the peptide immunogen, but not an unrelated peptide, greatly reduced the amount of ${ }^{125} \mathrm{I}-\mathrm{NGF}$ in the immune complexes (data not shown). Furthermore, the same amount of an irrelevant antibody (anti-CBP) did not precipitate ${ }^{125} \mathrm{I}-\mathrm{NGF}$ (Fig. 4A). To test the idea that NGF is retrogradely cotransported with $\operatorname{TrkA}$, distal axons of sympathetic neurons grown in compartmentalized cultures were treated with ${ }^{125} \mathrm{I}-\mathrm{NGF}$ (40 ng/ml) for $8 \mathrm{hr}$, a time when retrogradely transported NGF is readily detected (Claude et al., 1982). Distal axons of a parallel set of cultures were treated with ${ }^{125} \mathrm{I}-\mathrm{NGF}$ (40 $\mathrm{ng} / \mathrm{ml}$ ) and an excess of unlabeled NGF (500 $\mathrm{ng} / \mathrm{ml}$ ). Cultures were then washed extensively, protein extracts were prepared from individual compartments in the presence of the cross-linker $\mathrm{BS}^{3}$, and TrkA was immunoprecipitated. Coimmunoprecipitation of ${ }^{125} \mathrm{I}-\mathrm{NGF}$ was determined by resolving immunoprecipitates by SDS-PAGE followed by autoradiography. ${ }^{125}$ I-NGF coimmunoprecipitated with TrkA from extracts prepared from cell body compartments after distal axons and terminals were treated with ${ }^{125} \mathrm{I}-\mathrm{NGF}$; little or no ${ }^{125} \mathrm{I}-\mathrm{NGF}$ was detected when an excess of unlabeled NGF was also applied to the terminals, demonstrating specific transport of ${ }^{125}$ I-NGF (Fig. $4 B) .{ }^{125}$ I-NGF was undetectable in medium within the cell body compartments, indicating that ${ }^{125} \mathrm{I}-\mathrm{NGF}$ did not leak under the Teflon dividers.

To confirm further that the ${ }^{125}$ I-NGF-TrkA complex detected within cell bodies is derived from distal axons and terminals, experiments were performed in which TrkA localized on the cell surface of distal axons was biotinylated before exposure of the distal axons to ${ }^{125} \mathrm{I}-\mathrm{NGF}$ for $8 \mathrm{hr}$. Then, lysates of cell bodies and 


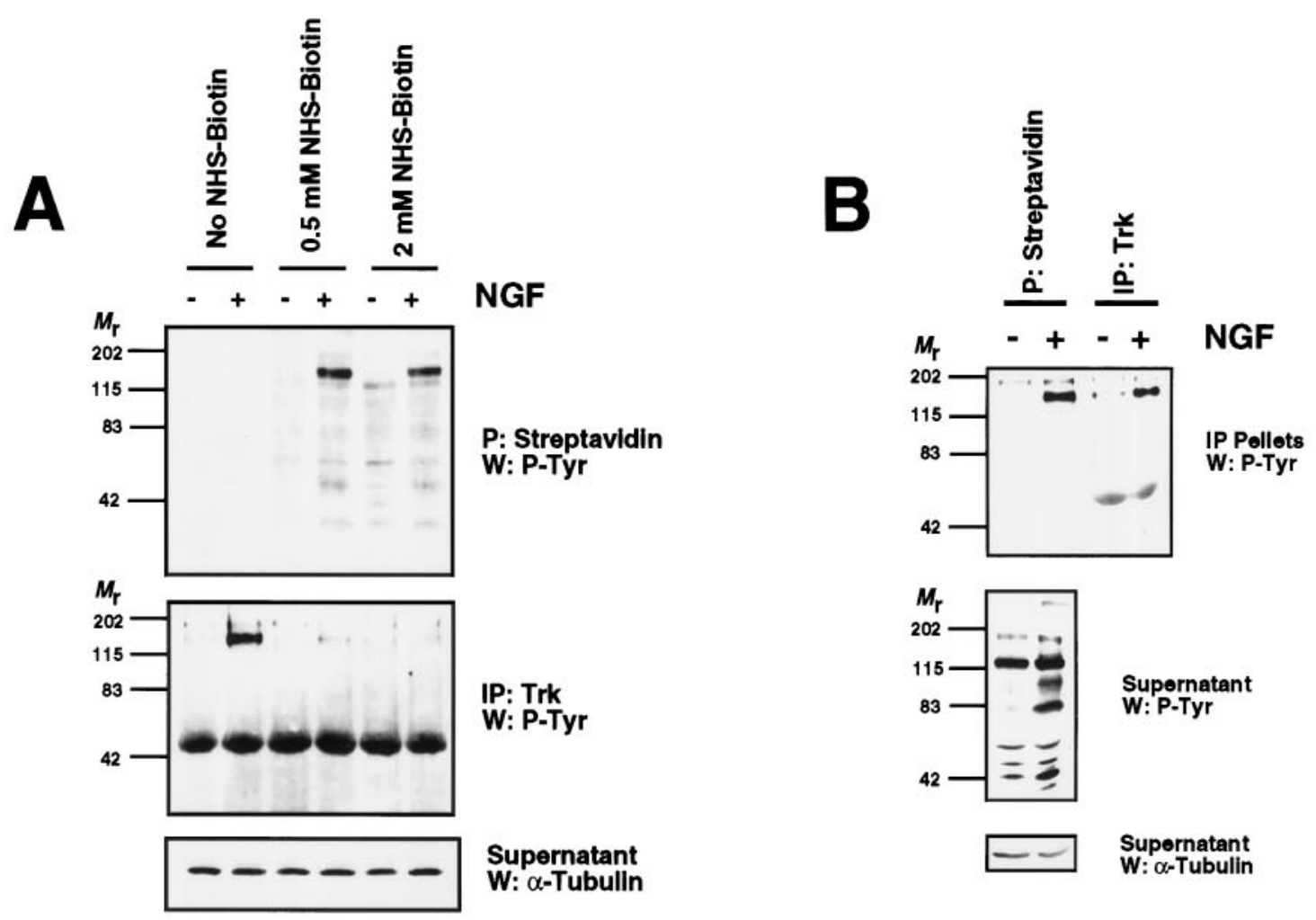

C
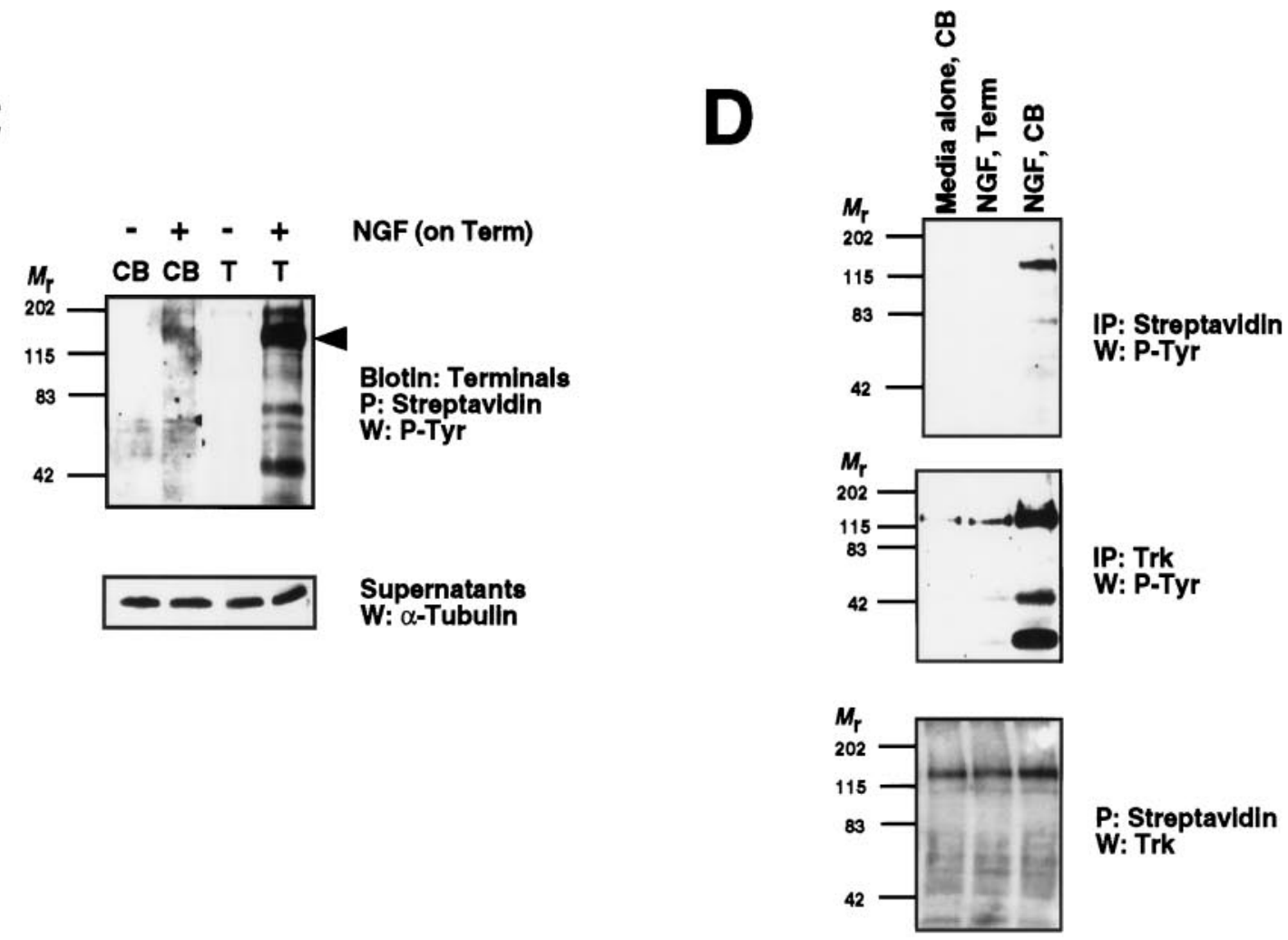

P: Streptavidin W: Trk

Figure 3. Phosphorylated TrkA is retrogradely transported in sympathetic neurons. A, Mass cultures of sympathetic neurons maintained for 12 DIV were incubated with $0,0.5$, or $2 \mathrm{mM}$ NHS-LC-biotin for $30 \mathrm{~min}$ at $4^{\circ} \mathrm{C}$ to biotinylate cell surface proteins. The neurons were then washed and treated with medium alone $(-)$ or medium containing NGF $(200 \mathrm{ng} / \mathrm{ml} ;+)$ for $10 \mathrm{~min}$. Biotinylated proteins were precipitated $(P)$ with immobilized streptavidin (top), and the supernatants of this precipitation were next subjected to Trk immunoprecipitation (middle). Precipitates were then electrophoresed on $8 \%$ SDS-polyacrylamide gels and subjected to phosphotyrosine immunoblotting. $\alpha$-Tubulin immunoblotting performed (Figure legend continues) 
distal axons and terminals were prepared and subjected to streptavidin precipitation under nondenaturing conditions. Immobilized streptavidin precipitated ${ }^{125} \mathrm{I}-\mathrm{NGF}$ from lysates of cell bodies after treatment of distal axons with ${ }^{125}$ I-NGF. Coprecipitation of ${ }^{125}$ I-NGF was abolished if excess unlabeled NGF (500 $\mathrm{ng} / \mathrm{ml}$ ) was added to distal axons and terminals to compete with ${ }^{125} \mathrm{I}-\mathrm{NGF}$ (Fig. 4D). As found previously, no ${ }^{125} \mathrm{I}-\mathrm{NGF}$ was detected in the medium directly bathing the cell bodies, demonstrating that ${ }^{125} \mathrm{I}-\mathrm{NGF}$ did not leak under the Teflon dividers. Finally, streptavidin precipitation of ${ }^{125}$ I-NGF was dependent on biotinylation of TrkA; no detectable ${ }^{125} \mathrm{I}-\mathrm{NGF}$ was precipitated with immobilized streptavidin if cell surface proteins were not biotinylated before treatment with ${ }^{125} \mathrm{I}-\mathrm{NGF}$ (Fig. $4 C$ ). We conclude that NGF binds to TrkA on the cell surface of axon terminals and that this NGF-TrkA complex is cotransported from distal axons and terminals to cell bodies.

\section{TrkA dephosphorylation is markedly faster in young, NGF-dependent neurons than in older, NGF- independent neurons after NGF withdrawal}

Our results indicate that TrkA and NGF are cotransported as a complex from distal axons to cell bodies. To determine the stability of the P-TrkA complex in mass cultures of sympathetic neurons, we measured the phosphorylation state of TrkA at various times after NGF withdrawal. NGF was replaced with anti-NGF in medium bathing either NGF-dependent 5 DIV neurons or NGF-independent 35 DIV sympathetic neurons. Then, phosphorylation of TrkA was assessed by immunoprecipitation of TrkA followed by phosphotyrosine immunoblotting. After NGF removal from young, NGF-dependent neurons, TrkA was rapidly dephosphorylated; P-TrkA was undetectable $1 \mathrm{hr}$ after NGF withdrawal (Fig. 5A). Kinetic analysis revealed that the half-life of P-TrkA in young, NGF-dependent neurons is between 10 and 20 min (data not shown). In contrast, dephosphorylation of TrkA was markedly slower in older, NGF-independent sympathetic neurons after NGF withdrawal; kinetic analysis revealed that the half-life of P-TrkA in 35 DIV neurons is $>4 \mathrm{hr}$ (Fig. $5 A$ ) (data not shown). Thus, the rate of TrkA dephosphorylation is dramatically different in young, NGF-dependent neurons compared with older, NGF-independent neurons.

We hypothesized that the dramatic differences in kinetics of dephosphorylation of P-TrkA between NGF-dependent and -independent sympathetic neurons could be caused by a difference in the levels of activity of P-TrkA phosphatase in these neurons. To test this idea, we treated both 5 and 35 DIV mass cultures of sympathetic neurons with the potent and specific inhibitor of Trk kinase activity K252a (Berg et al., 1992; Ohmichi et al., 1992; Tapley et al., 1992). P-TrkA became rapidly dephosphorylated in both NGF-dependent and -independent neurons after only $15 \mathrm{~min}$ of K252a treatment (Fig. $5 B$ ). The extent of dephosphorylation of TrkA was slightly greater in young neurons. As found previously, there was little change in the level of TrkA phosphorylation after 90 min of NGF withdrawal from 35 DIV neurons, whereas this treatment led to a nearly complete dephosphorylation of TrkA in 5 DIV neurons (Fig. 5B). Therefore, differences in the amounts or activities of P-TrkA phosphatases cannot completely account for the dramatic differences in the stability of P-TrkA after NGF withdrawal from young versus old neurons.

\section{P-TrkA in the cell bodies is sensitive to the presence of NGF on the terminals of NGF-dependent, but not NGF-independent, sympathetic neurons}

Tyrosine phosphorylation of TrkA within distal processes as well as cell bodies is sensitive to the presence of NGF in medium bathing distal axons of young, NGF-dependent sympathetic neurons. Moreover, TrkA remains tyrosine-phosphorylated for an unusually long period of time in mature, NGF-independent sympathetic neurons after NGF withdrawal (Fig. 5). To determine whether there are age-dependent differences in the metabolism of P-TrkA in cell bodies and proximal axons as well as in distal axons, we assessed TrkA dephosphorylation in young and old neurons grown in compartmentalized cultures after removal of NGF from their distal axons. For these experiments, the state of tyrosine phosphorylation of TrkA from 12 DIV neurons, rather than 5 DIV neurons, was compared with P-TrkA from 35 DIV neurons because we found that it takes $12 \mathrm{~d}$ for the axons of sympathetic neurons to extend fully through the barriers of compartmentalized chambers under our culture conditions. Like 5 DIV neurons, 12 DIV neurons are absolutely dependent on NGF for survival (data not shown). Twelve DIV neurons were grown for several days in medium containing NGF bathing distal axons and terminals and medium containing anti-NGF bathing cell bodies. Then, NGF in the medium bathing distal axons and terminals was replaced by anti-NGF for times up to $12 \mathrm{hr}$. TrkA immunoprecipitations were performed on extracts prepared from both the cell body and the distal axon compartments at each time point, and the levels of P-TrkA were assessed by phosphotyrosine immunoblotting. P-TrkA in distal axons and terminals became rapidly dephosphorylated after NGF withdrawal from the distal axons and terminals (Fig. 6A). Likewise, P-TrkA disappeared from the cell bodies after NGF withdrawal from terminals of 12

\footnotetext{
on the supernatants of the immunoprecipitates denotes equal protein loading (bottom). B, Cell surface proteins of mass cultures of sympathetic neurons grown in medium containing anti-NGF for $7 \mathrm{hr}$ were biotinylated as described in $A$ and treated with medium alone (-) or medium containing NGF (200 $\mathrm{ng} / \mathrm{ml} ;+)$. Lysates from these treatments were first subjected to a nonstoichiometric Trk immunoprecipitation followed by a precipitation with immobilized streptavidin, as labeled above each lane. The precipitates (top) as well as the supernatants from this analysis (middle) were subjected to phosphotyrosine immunoblotting, and supernatants were subjected to $\alpha$-tubulin immunoblotting (bottom) to normalize for protein amounts in the lysates. $C$, Compartmentalized cultures were chilled to $4^{\circ} \mathrm{C}$, and plasma membrane proteins of distal axons and terminals were subjected to biotinylation, while the cell body compartments were left untreated. Compartmentalized cultures were then washed extensively and warmed to $37^{\circ} \mathrm{C}$, and distal axons and terminals were treated with either medium alone $(-)$ or medium containing NGF $(200 \mathrm{ng} / \mathrm{ml} ;+)$ for 2 hr. Extracts prepared from both the cell body and distal axons and terminal compartments were subjected to immobilized streptavidin precipitations, and the precipitants were subjected to phosphotyrosine immunoblot analysis (top). $\alpha$-Tubulin immunoblot analysis performed on supernatants of the precipitation is shown (bottom). This experiment was performed three times with independent cultures with similar results. $D$, Membrane proteins of cell bodies were biotinylated, while distal axons and terminals were left untreated. Then, cultures were warmed to $37^{\circ} \mathrm{C}$, and either the cell bodies were treated with medium alone, the cell bodies were treated with medium containing NGF $(200 \mathrm{ng} / \mathrm{ml})$, or the distal axons and terminals were treated with medium containing NGF (200 ng/ml). Biotinylated proteins were precipitated first using immobilized streptavidin (top), and the supernatants subsequently were subjected to immunoprecipitation using anti-Trk C14 (middle); both precipitates were then subjected to phosphotyrosine immunoblotting. The top immunoblot was reprobed with a Trk antibody to demonstrate equal precipitation of TrkA in all three conditions (bottom). Only precipitations from cell body compartments are shown.
} 
A
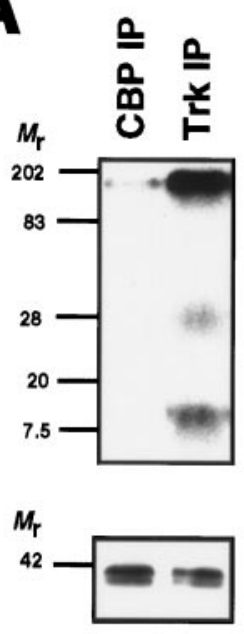

IP Pellets Autoradlography

\section{Supernatants
W: MAPK \\ Supernatants
W: MAPK}

C

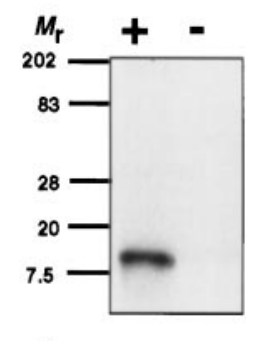

NHS-Blotin

P: Streptavidin Autoradlography

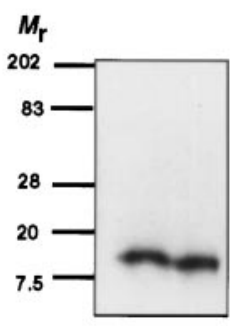

IP: Trk Autoradlography

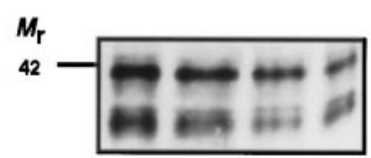

\section{D}

[125]]NGF (on Term) - Excess NGF (on Term)

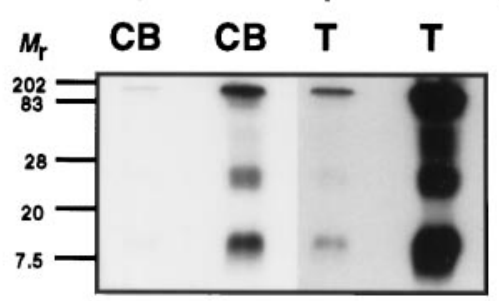

IP: Trk

Autoradlography

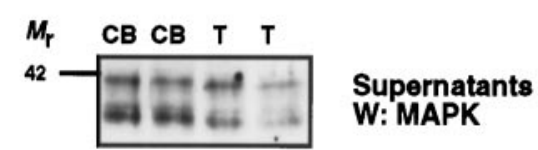

W: MAPK
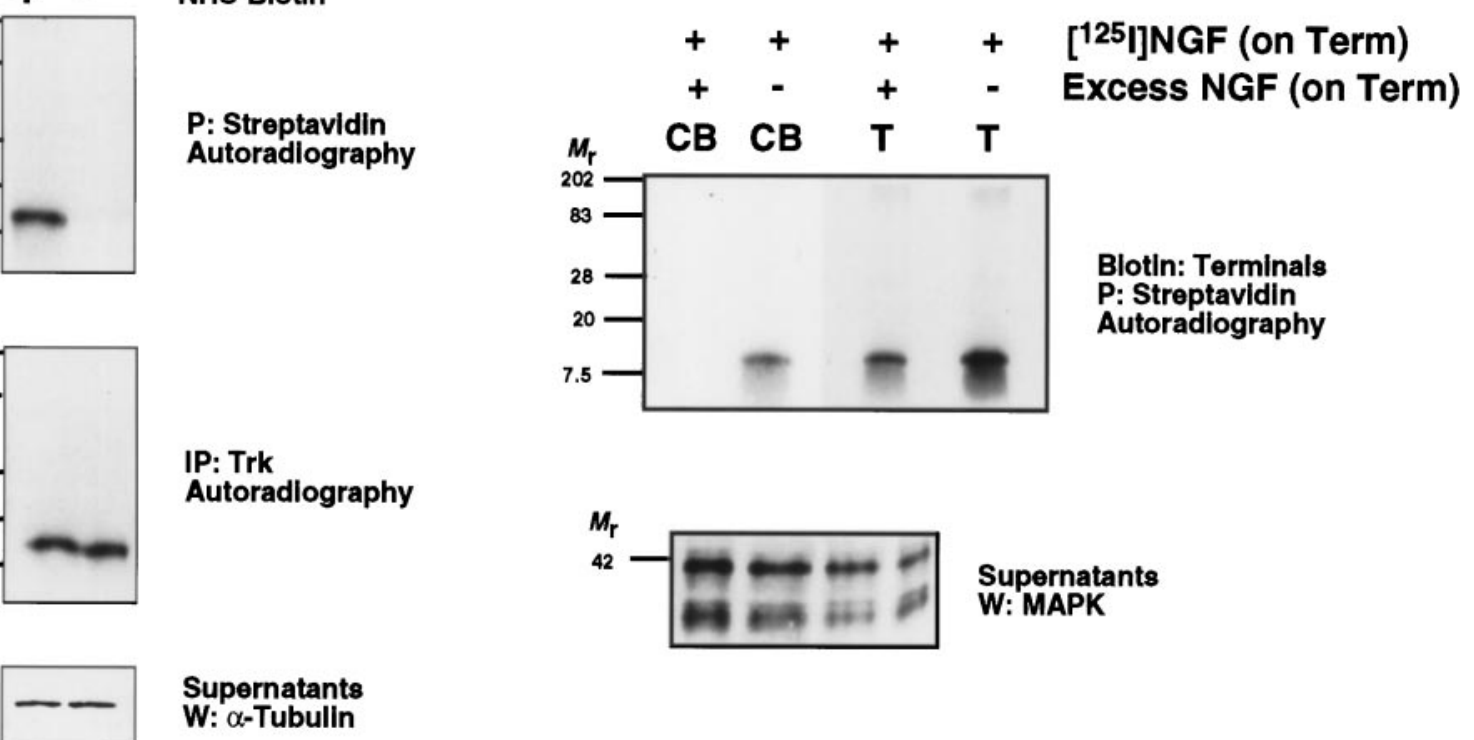

Supernatants

W: $\alpha$-Tubulin

Figure 4. NGF and TrkA are cotransported from distal axons and terminals to cell bodies after NGF treatment of distal axons and terminals. $A$, Mass cultures of sympathetic neurons were treated with ${ }^{125} \mathrm{I}-\mathrm{NGF}(40 \mathrm{ng} / \mathrm{ml})$ for $30 \mathrm{~min}$ at $37^{\circ} \mathrm{C}$, washed, and subjected to cross-linking in lysis buffer containing $2 \mathrm{mM} \mathrm{BS}^{3}$. Immunoprecipitations were next performed using either C14 Trk (1:200) or CBP (1:200) rabbit polyclonal antibodies under identical conditions. The immunoprecipitates were resolved on 15\% SDS-polyacrylamide gels and next analyzed for the presence of ${ }^{125}$ I-NGF by autoradiography (top). Equal protein loading was determined by probing immunoblots of supernatants of the immunoprecipitates with anti-MAPK (bottom). B, Distal axons and terminals of neurons grown in biochemistry chambers were treated with ${ }^{125} \mathrm{I}-\mathrm{NGF}$ (40 ng/ml) or with ${ }^{125} \mathrm{I}-\mathrm{NGF}$ (40 ng/ml) and excess unlabeled NGF $(500 \mathrm{ng} / \mathrm{ml})$ for $8 \mathrm{hr}$. Extracts prepared from both the cell body and distal axon and terminal compartments were subjected to cross-linking and Trk immunoprecipitation, and the immune complexes were analyzed as described in $A$ (top). Anti-MAPK immunoblots were performed on supernatants of the immunoprecipitates to confirm that equal amounts of protein were present in the extracts (bottom). This experiment was performed four times using independent cultures with similar results. $C$, Cell surface proteins of neurons grown in mass culture were biotinylated as described in Figure 3. Then neurons were treated with $40 \mathrm{ng} / \mathrm{ml}{ }^{125} \mathrm{I}$-NGF for $30 \mathrm{~min}$, washed, and subjected to immobilized streptavidin precipitation (top) or Trk immunoprecipitation (middle) without previous cross-linking. Precipitates were analyzed as described in $A$, and equal protein loading was determined by $\alpha$-tubulin immunoblot analysis on supernatants of the precipitates (bottom). $D$, Distal axons and terminals of neurons grown in biochemistry chambers were biotinylated and then treated with either $40 \mathrm{ng} / \mathrm{ml}{ }^{125} \mathrm{I}-\mathrm{NGF}$ or $40 \mathrm{ng} / \mathrm{ml}{ }^{125} \mathrm{I}$-NGF with an excess of unlabeled NGF (500 $\mathrm{ng} / \mathrm{ml}$ ) for $8 \mathrm{hr}$. Extracts prepared from the cell body and distal axon and terminal compartments were subjected to immobilized streptavidin precipitation followed by 15\% SDS-PAGE and autoradiography (top). Identical results were obtained from two independent cultures. Equal protein loading was determined with anti-MAPK immunoblot analysis (bottom). $P$, precipitation; $W$, Western blot. 
A
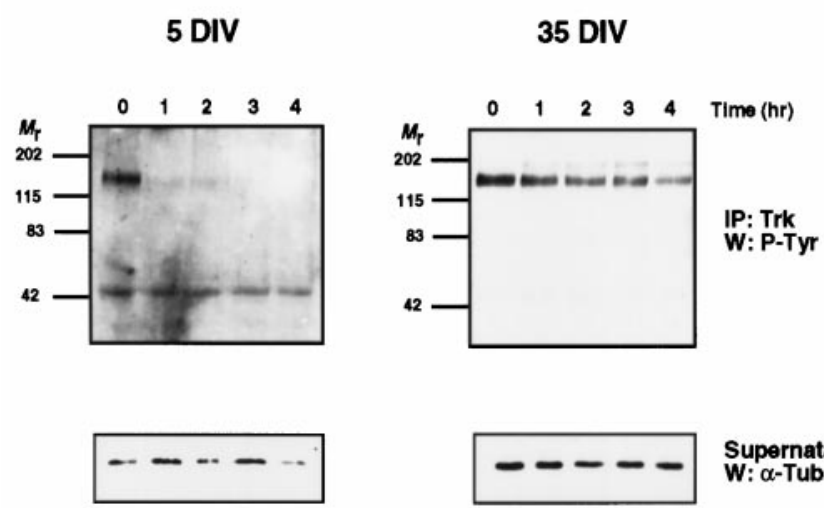

Supernatant W: $\alpha$-Tubulin

B
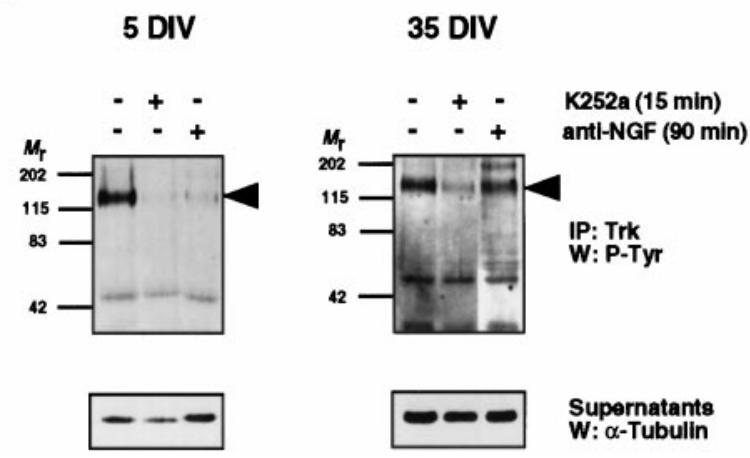

Figure 5. TrkA dephosphorylation is markedly faster in young, NGFdependent neurons than in older, NGF-independent neurons after NGF withdrawal. $A$, Medium containing NGF was replaced with medium containing anti-NGF in NGF-dependent (5 DIV; left panels) or NGFindependent (35 DIV; right panels) sympathetic neurons grown in mass culture. Then, TrkA was immunoprecipitated at the times indicated above the panels, and immune complexes were subjected to phosphotyrosine immunoblotting (top). Supernatants of immunoprecipitations were subjected to $\alpha$-tubulin immunoblotting (bottom). B, Five DIV (left panels) or 35 DIV (right panels) mass cultures of sympathetic neurons were treated with control growth medium (left lanes), growth medium containing $\mathrm{K} 252 \mathrm{a}(200 \mathrm{nM})$ for $15 \mathrm{~min}$ (middle lanes), or medium containing antiNGF for 90 min (right lanes). Then, TrkA was immunoprecipitated and subjected to phosphotyrosine immunoblotting as above.

DIV sympathetic neurons; P-TrkA in the cell bodies was undetectable by $6 \mathrm{hr}$ (Fig. 6A). Phosphotyrosine immunoblot analysis was also performed on the supernatants from the TrkA immunoprecipitations. Most tyrosine-phosphorylated proteins also became dephosphorylated in a time-dependent manner in the distal axons and terminals after NGF removal. Unexpectedly, there was a time-dependent increase in tyrosine phosphorylation of proteins detected in extracts prepared from the cell bodies after NGF withdrawal from the distal axons; this effect peaked by $6 \mathrm{hr}$ and declined thereafter (Fig. 6B). The phosphorylation state of almost all tyrosine-phosphorylated proteins in cell bodies was consistently upregulated after NGF withdrawal from the terminals, suggesting that NGF withdrawal from distal axons leads to a decrease in the activity of one or more generally acting protein tyrosine phosphatases in cell bodies.

In contrast to that of 12 DIV neurons, the kinetics of TrkA dephosphorylation was quite slow for 35 DIV sympathetic neurons grown in compartmentalized cultures. As for 12 DIV neurons, NGF was removed from the distal axons and terminals of 35 DIV neurons grown with NGF only present in the medium bathing distal axons and terminals. P-TrkA disappeared from distal axons and terminals within $9 \mathrm{hr}$ after NGF removal; this was somewhat slower than that observed for 12 DIV neurons. More dramatically, the level of P-TrkA in the cell bodies remained unchanged $12 \mathrm{hr}$ after NGF withdrawal from the terminals (Fig. 6A). In fact, NGF removal from distal axons and terminals for 24 and $52 \mathrm{hr}$ resulted in only a modest, $\sim 50 \%$ decrease in the levels of P-TrkA in the cell bodies (Fig. 6C). The tyrosine phosphorylation state of proteins in supernatants of Trk immunoprecipitations were also analyzed. After NGF removal from distal axons, tyrosine phosphorylation of most proteins in the distal axons was diminished, whereas tyrosine phosphorylation of proteins in cell bodies was increased, similar to results obtained with young, NGF-dependent sympathetic neurons (Fig. $6 B$ ). Thus, in distal axons and terminals of both NGF-dependent and -independent sympathetic neurons, tyrosine phosphorylation of TrkA is regulated by NGF. In contrast, although tyrosine phosphorylation of TrkA in cell bodies of young neurons is absolutely dependent on the presence of NGF on distal axons, the amount of P-TrkA in cell bodies of older, NGF-independent neurons is remarkably insensitive to removal of NGF from distal axonal processes.

\section{DISCUSSION}

In this study we sought to determine whether an NGF-P-TrkA complex is a retrograde signal in sympathetic neurons and whether metabolism of the NGF-P-TrkA complex is different between young, NGF-dependent neurons and older, NGFindependent neurons. Our results indicate that, after activation by NGF, TrkA forms a complex with at least seven tyrosinephosphorylated proteins in the cell bodies and proximal axons, as well as the distal axons and terminals of sympathetic neurons. Furthermore, P-TrkA that appears in cell bodies after treatment of terminals with NGF is associated with at least three of these tyrosine-phosphorylated proteins. After treatment of the distal processes with NGF, P-TrkA that appears in the cell bodies is, at least in part, derived via retrograde transport from distal axons and terminals. NGF forms a complex with TrkA in distal processes, and this complex is retrogradely transported to cell bodies, perhaps with associated substrates of TrkA.

Retrograde transport of an NGF-P-TrkA complex in sympathetic neurons is consistent with studies that have demonstrated that NGF is retrogradely transported in vivo (Hendry et al., 1974; Korsching and Thoenen, 1983) and in compartmentalized cultures in vitro (Claude et al., 1982; Ure and Campenot, 1997). Furthermore, P-TrkA and P-TrkB accumulate distal to a nerve ligation (Ehlers et al., 1995; Bhattacharyya et al., 1997) or nerve crush (Johanson et al., 1995) and in cell bodies of sympathetic neurons grown in compartmentalized cultures (Riccio et al., 1997; Senger and Campenot, 1997). Importantly, catalytically active, autophosphorylated TrkA within the cell body appears to be a critical mediator of retrograde signaling in sympathetic neurons (Riccio et al., 1997; Senger and Campenot, 1997). Yet, whether P-TrkA detected in cell bodies is derived from P-TrkA that had been retrogradely transported from axon terminals or 
A

12 DIV
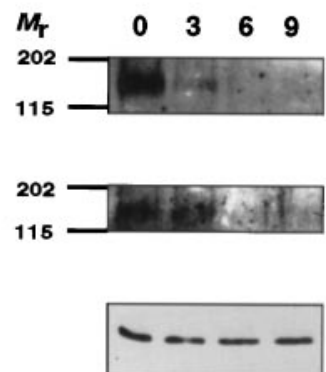

anti-NGF (on term)

Torminals

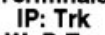

W: P-Tyr

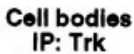

IP: Trk

Cell bodies

Supernatants

W: $\alpha$-Tubulin
35 DIV
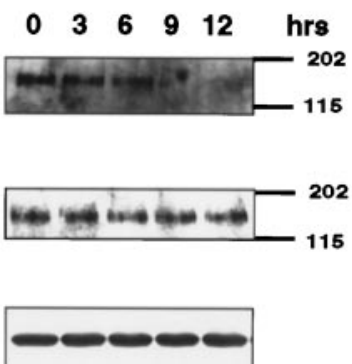

\section{DIV}

B

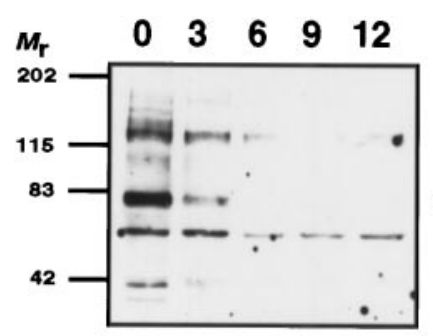

anti-NGF
(term)

Torminals

Supernatants

W: P-Tyr
35 DIV
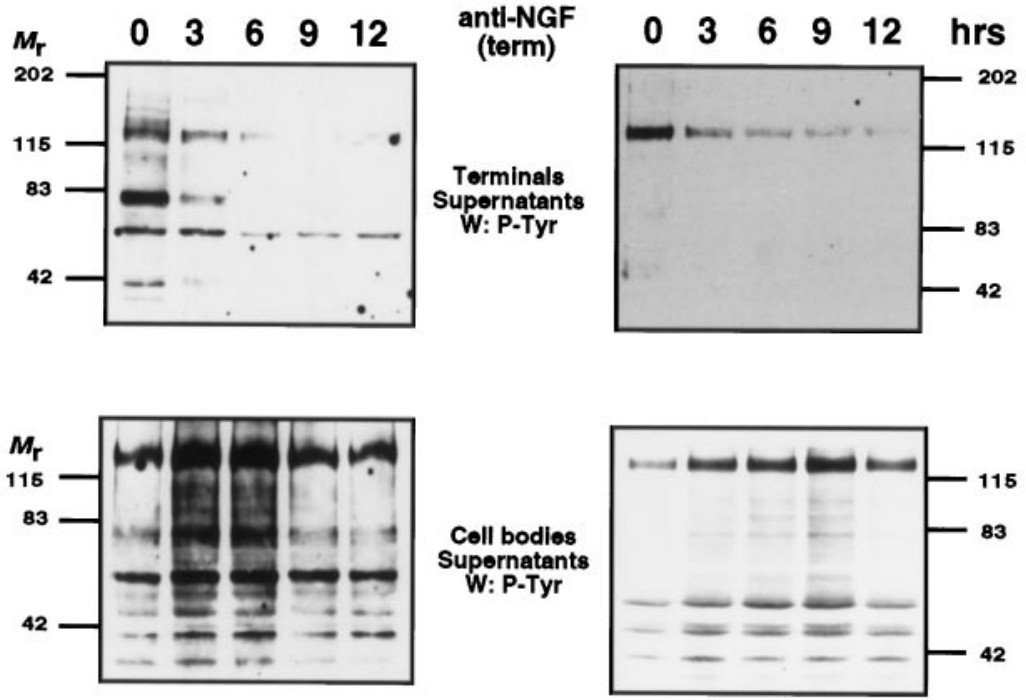

Figure 6. Tyrosine phosphorylation of TrkA localized in cell bodies of mature, NGF-independent sympathetic neurons in the absence of NGF. A, Twelve DIV NGF-dependent neurons (left) and 35 DIV NGFindependent neurons (right) were grown in compartmentalized cultures with medium containing anti-NGF in cell body compartments and with medium containing NGF $(200 \mathrm{ng} / \mathrm{ml})$ in distal axon and terminal compartments for several days. Media in distal axon and terminal compartments were replaced with media containing anti-NGF for the indicated times (in hours). Then, TrkA was immunoprecipitated from extracts prepared from either cell bodies (middle) or distal axons and terminals (top), and immune complexes and supernatants of immunoprecipitates were subjected to phosphotyrosine immunoblot analysis. Similar results were obtained from three to four independent experiments. $B$, Supernatants of the immunoprecipitates from $A$ were subjected to phosphotyrosine immunoblotting. $C$, Thirty-five DIV NGF-independent neurons were grown in compartmentalized cultures with medium containing anti-NGF in cell body compartments and with medium containing NGF $(200 \mathrm{ng} / \mathrm{ml})$ in distal axon and terminal compartments for several days. Medium in distal axon and terminal compartfor 0,24 , or $52 \mathrm{hr}$. Then, TrkA was immunoprecipitated from extracts prepared from either cell bodies (middle) plexes were subjected to phosphotyrosine immunoblot analysis. ments was replaced with media containing anti-NGF or distal axons and terminals (top), and immune com-
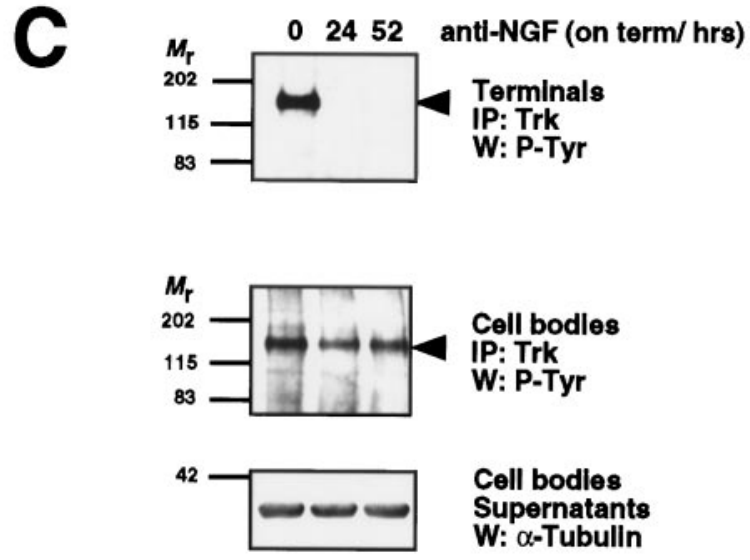

TrkA that had been activated within cell bodies by retrogradely transported NGF or some other signaling mechanism has been unclear. Our results provide direct evidence that P-TrkA is retrogradely transported from distal axons and terminals to cell bodies of neonatal sympathetic neurons. Moreover, retrogradely transported NGF and retrogradely transported TrkA are found in a complex within the cell bodies, strongly suggesting that these molecules are retrogradely cotransported. Although several 
tyrosine-phosphorylated proteins were detected in association with retrogradely transported P-TrkA in cell bodies, our experiments cannot distinguish between the possibilities that these substrates cotransport with P-TrkA from distal processes or that they associate with P-TrkA after its arrival in the cell body. Furthermore, because of the limitations of detection attributable to extremely small numbers of neurons, we could not definitively identify the TrkA substrates found associated with retrogradely transported TrkA. These analyses must await more sensitive antigen detection methods than those described here. However, because PLC- $\gamma$ remains associated with P-TrkA in internalized endosomes purified from NGF-treated pheochromocytoma (PC12) cells (Grimes et al., 1996), it is likely that at least some substrates will remain tightly associated with P-TrkA in retrograde-signaling endosomes in sympathetic neurons. Defining the nature of the retrograde-signaling endosome, which is likely to be similar or identical to a P-TrkA-containing endosome purified from PC12 cells (Grimes et al., 1996, 1997), and its mechanism of axonal transport remain important current challenges.

NGF treatment of distal processes leads to robust phosphorylation of TrkA, but only a small percentage of P-TrkA is retrogradely transported to the cell bodies. These observations parallel results of experiments that examined retrograde transport of NGF in compartmentalized cultures of sympathetic neurons; only $2 \%$ of ${ }^{125} \mathrm{I}-\mathrm{NGF}$ that associated with receptors on distal axons and terminals is transported to the cell bodies per hour (Ure and Campenot, 1997). Similarly, in the present study, only $2.5 \%$ of the amount of ${ }^{125}$ I-NGF that coprecipitated with TrkA from distal processes was found to coprecipitate with TrkA from cell bodies after exposure of ${ }^{125} \mathrm{I}-\mathrm{NGF}$ to the distal axons for $8 \mathrm{hr}$. These results indicate that only a small fraction of TrkA that is activated in distal axons undergoes retrograde transport to cell bodies in compartmentalized cultures. However, $>40 \%$ of retrogradely transported ${ }^{125}$ I-NGF detected in extracts of cell bodies coprecipitated with TrkA. This number is likely to be an underestimation of the fraction of NGF complexed with TrkA in cell bodies and proximal processes because some of the ${ }^{125} \mathrm{I}-\mathrm{NGF}-\mathrm{TrkA}$ complex may have dissociated during the coprecipitation procedure. Thus, although a minor fraction of NGF and TrkA is retrogradely transported to cell bodies, a major fraction of NGF that is retrogradely transported is bound to retrogradely transported TrkA.

During the course of studying NGF-dependent TrkA phosphorylation of sympathetic neurons, we observed striking differences in the metabolism of P-TrkA between young, NGFdependent and older, NGF-independent sympathetic neurons when grown both in mass cultures and compartmentalized cultures. P-TrkA within cell bodies of NGF-independent sympathetic neurons is remarkably stable and relatively insensitive to changes in levels of extracellular NGF. One trivial explanation we considered to explain the dramatic differences in levels of P-TrkA after NGF withdrawal from 5 and 35 DIV neurons is that axonal arborizations of 35 DIV neurons are more extensive than those of younger neurons so that the distance internalized TrkA may have to travel before it is dephosphorylated is longer. However, the distance between the cell bodies and distal processes is the same for young and old compartmentalized neurons $(1 \mathrm{~mm})$, and P-TrkA was detected in cell bodies of 35 DIV neurons long after it had disappeared from the distal axons (Fig. 6C). Therefore, axon length cannot account for the near constant levels of P-TrkA in cell bodies of older, NGF-independent neurons after with- drawal of NGF from distal axons. Another possibility is that TrkA could remain phosphorylated after NGF withdrawal in NGFindependent neurons because of autocrine secretion of a factor into the medium, such as NT-3, which can activate TrkA. However, conditioned medium experiments demonstrated that NGFindependent neurons do not secrete a factor into the medium that maintains TrkA phosphorylation (data not shown). Therefore, we favor one of several other possible models to account for the dramatic differences in metabolism of P-TrkA in young and old sympathetic neurons. First, internalized P-TrkA could be more stable in old versus young neurons, which could lead to an accumulation of P-TrkA in the cell bodies. Pulse-chase experiments could address this possibility. Second, TrkA phosphorylation could be regulated within the cell body in an extracellular NGFindependent manner. For example, an intracellular or membraneattached activator of TrkA or a change in the membrane lipid composition (Ferrari et al., 1995; Rabin and Mocchetti, 1995) could enhance TrkA catalytic activity in older neurons. Third, there could be an age-dependent regulation of a protein tyrosine phosphatase (PTP) that dephosphorylates TrkA. Although K252a treatment led to dephosphorylation of the majority of TrkA in both old and young neurons, a higher percentage of TrkA remained phosphorylated in 35 DIV neurons compared with 5 DIV neurons when grown in mass cultures. Therefore, we cannot rule out the possibility that cell bodies of older neurons contain relatively low amounts of TrkA phosphatase activity. The potential roles of TrkA degradation, intracellular ligands, TrkA substrates, p75, membrane lipids, and PTPs in regulating the metabolism of P-TrkA in an age-dependent manner await further investigation.

The observation that TrkA remains tyrosine-phosphorylated in 35 DIV neurons raises the interesting possibility that adult sympathetic neurons may still require TrkA catalytic activity for survival. Although sympathetic neurons are dependent on NGF for survival during development (Levi-Montalcini and Booker, 1960; Levi-Montalcini, 1987), these neurons lose their dependence on NGF for survival in adulthood (Angeletti et al., 1971; Bjette et al., 1975; Goedert et al., 1978). A transition from NGF dependence to NGF independence for survival also occurs in sympathetic neurons grown in vitro (Lazarus et al., 1976; Chun and Patterson, 1977; Easton et al., 1997). The biochemical changes responsible for the transition of NGF dependence to NGF independence for survival of sympathetic neurons are not well understood (Easton et al., 1997). Our results suggest a model in which a pool of P-TrkA within cell bodies of adult sympathetic neurons, which is insensitive to NGF withdrawal, contributes to survival of these neurons after NGF withdrawal. Thus, it will be of interest to determine whether age-dependent changes in P-TrkA metabolism are a general phenomenon for this receptor in all NGF-responsive neurons in vitro and in vivo and whether adult NGF-independent sympathetic neurons are dependent on TrkA activity for survival.

\section{REFERENCES}

Angeletti PU, Levi-Montalcini R, Caramia F (1971) Analysis of the effects of the antiserum to the nerve growth factor in adult mice. Brain Res 27:343-355.

Barde Y-A (1989) Trophic factors and neuronal survival. Neuron 2:1525-1534.

Berg MM, Sternberg DW, Parada LF, Chao MV (1992) K-252a inhibits nerve growth factor-induced trk proto-oncogene tyrosine phosphorylation and kinase activity. J Biol Chem 267:13-16.

Bhattacharyya A, Watson F, Bradlee T, Pomeroy S, Stiles C, Segal R 
(1997) Trk receptors function as rapid retrograde signal carriers in the adult nervous system. J Neurosci 17:7007-7016.

Bjette B, Wilkund L, Edwards DC (1975) A study of the de- and regenerative changes in the sympathetic nervous system of the adult mouse after treatment with antisera to NGF. Brain Res 92:257-278.

Bothwell M (1995) Functional interactions of neurotrophins and neurotrophin receptors. Annu Rev Neurosci 18:223-253.

Campenot RB (1982) Development of sympathetic neurons in compartmentalized cultures. Dev Biol 93:1-12.

Chun LLY, Patterson PH (1977) Role of nerve growth factor in the development of rat sympathetic neurons in vitro. II. Developmental studies. J Cell Biol 75:705-711.

Claude P, Hawrot E, Dunis DA, Campenot RB (1982) Binding, internalization and retrograde transport of 125I-nerve growth factor in cultured rat sympathetic neurons. J Neurosci 2:431-442.

Easton RM, Deckwerth TL, Parsadanian AS, Johnson Jr EM (1997) Analysis of the mechanism of loss of trophic factor dependence associated with neuronal maturation: a phenotype indistinguishable from Bax deletion. J Neurosci 17:9656-9666.

Ehlers MD, Kaplan DR, Price DL, Koliatsos VE (1995) NGFstimulated retrograde transport of TrkA in the mammalian nervous system. J Cell Biol 130:149-156.

Ferrari G, Anderson BL, Stephens RM, Kaplan DR, Greene LA (1995) Prevention of apoptotic neuronal death by GM1 ganglioside: involvement of Trk neurotrophin receptors. J Biol Chem 270:3074-3080.

Goedert M, Otten U, Thoenen H (1978) Biochemical effects of antibodies against nerve growth factor on developing and differentiated sympathetic ganglia. Brain Res 148:264-268.

Greene LA, Kaplan DR (1995) Early events in neurotrophin signalling via Trk and p75. Curr Opin Neurobiol 5:579-587.

Grimes ML, Zhou J, Beattle EC, Yuen EC, Hall DE, Valletta JS, Topp KS, LaVail JH, Bunnett NW, Mobley WC (1996) Endocytosis of activated TrkA: evidence that nerve growth factor induces formation of signaling endosomes. J Neurosci 16:7950-7964.

Grimes ML, Beattie E, Mobley WC (1997) A signaling organelle containing the nerve growth factor-activated receptor tyrosine kinase, TrkA. Proc Natl Acad Sci USA 94:9909-9914.

Hendry IA, Stockel K, Thoenen H, Iversen LL (1974) The retrograde axonal transport of nerve growth factor. Brain Res 68:103-121.

Johanson SO, Crouch MF, Hendry IA (1995) Retrograde axonal transport of signal transduction proteins in rat sciatic nerve. Brain Res 690:55-63.

Kaplan D, Martin-Zanca D, Parada LF (1991) Tyrosine phosphorylation and tyrosine kinase activity of the trk proto-oncogene product induced by NGF. Nature 350:158-160.

Kaplan DR, Stephens RM (1994) Neurotrophin signal transduction by the trk receptor. J Neurobiol 25:1404-1417.
Korsching S (1993) The neurotrophic concept: a reexamination. J Neurosci 13:2739-2748.

Korsching S, Thoenen H (1983) Quantitative demonstration of the retrograde axonal transport of endogenous nerve growth factor. Neurosci Lett 39:1-4.

Lazarus KJ, Bradshaw RA, West NR, Bunge RP (1976) Adaptive survival of rat sympathetic neurons cultured without supporting cells or exogenous nerve growth factor. Brain Res 113:159-164.

Levi-Montalcini R (1987) The nerve growth factor 35 years later. Science 237:1154-1162.

Levi-Montalcini R, Booker B (1960) Destruction of the sympathetic ganglia in mammals by an antiserum to a nerve growth protein. Proc Natl Acad Sci USA 42:695-699.

Mains RE, Patterson PH (1973) Primary cultures of dissociated sympathetic neurons. I. Establishment of long-term culture and studies of differentiated properties. J Cell Biol 59:329-345.

Mobley WC, Schenker A, Shooter EM (1976) Characterization and isolation of proteolytically modified nerve growth factor. Biochemistry 15:5543-5551.

Ohmichi M, Decker SJ, Pang L, Saltiel AR (1992) Inhibition of the cellular actions of nerve growth factor by staurosporine and K252a results from the attenuation of the activity of the trk tyrosine kinase. Biochemistry 31:4034-4039.

Oppenheim RW (1991) Cell death during development of the nervous system. Annu Rev Neurosci 14:453-501.

Rabin SJ, Mocchetti I (1995) GM1 ganglioside activates the high affinity nerve growth factor receptor trkA. J Neurochem 65:347-354.

Reichardt LF, Fariñas I (1997) Neurotrophic factors and their receptors: roles in neuronal development and function. In: Molecular and cellular approaches to neural development (Cowan WM, Jessel TM, Zipursky SL, eds), pp 220-263. New York: Oxford UP.

Riccio A, Pierchala B, Ciarallo C, Ginty DD (1997) An NGF-TrkAmediated retrograde signal to transcription factor CREB in sympathetic neurons. Science 227:1097-1100.

Segal RA, Greenberg ME (1996) Intracellular signaling pathways activated by neurotrophic factors. Annu Rev Neurosci 19:463-489.

Senger D, Campenot R (1997) Rapid retrograde tyrosine phosphorylation of TrkA and other proteins in rat sympathetic neurons in compartmented cultures. J Cell Biol 138:411-421.

Snider WD (1994) Functions of the neurotrophins during nervous system development. Cell 77:627-638.

Tapley P, Lamballe F, Barbacid M (1992) K252a is a selective inhibitor of the tyrosine protein kinase activity of the trk family of oncogenes and neurotrophin receptor. Oncogene 7:371-381.

Ure DR, Campenot RB (1997) Retrograde transport and steady-state distribution of ${ }^{125} \mathrm{I}$-nerve growth factor in rat sympathetic neurons in compartmentalized cultures. J Neurosci 17:1282-1290. 